NASA/TM—2007-214704

\title{
Lunar Simulation in the Lunar Dust Adhesion Bell Jar
}

James R. Gaier

Glenn Research Center, Cleveland, Ohio

Edward A. Sechkar

QSS Group, Inc., Cleveland, Ohio 


\section{NASA STI Program . . . in Profile}

Since its founding, NASA has been dedicated to the advancement of aeronautics and space science. The NASA Scientific and Technical Information (STI) program plays a key part in helping NASA maintain this important role.

The NASA STI Program operates under the auspices of the Agency Chief Information Officer. It collects, organizes, provides for archiving, and disseminates NASA's STI. The NASA STI program provides access to the NASA Aeronautics and Space Database and its public interface, the NASA Technical Reports Server, thus providing one of the largest collections of aeronautical and space science STI in the world. Results are published in both non-NASA channels and by NASA in the NASA STI Report Series, which includes the following report types:

- TECHNICAL PUBLICATION. Reports of completed research or a major significant phase of research that present the results of NASA programs and include extensive data or theoretical analysis. Includes compilations of significant scientific and technical data and information deemed to be of continuing reference value. NASA counterpart of peer-reviewed formal professional papers but has less stringent limitations on manuscript length and extent of graphic presentations.

- TECHNICAL MEMORANDUM. Scientific and technical findings that are preliminary or of specialized interest, e.g., quick release reports, working papers, and bibliographies that contain minimal annotation. Does not contain extensive analysis.

- CONTRACTOR REPORT. Scientific and technical findings by NASA-sponsored contractors and grantees.
- CONFERENCE PUBLICATION. Collected papers from scientific and technical conferences, symposia, seminars, or other meetings sponsored or cosponsored by NASA.

- SPECIAL PUBLICATION. Scientific, technical, or historical information from NASA programs, projects, and missions, often concerned with subjects having substantial public interest.

- TECHNICAL TRANSLATION. Englishlanguage translations of foreign scientific and technical material pertinent to NASA's mission.

Specialized services also include creating custom thesauri, building customized databases, organizing and publishing research results.

For more information about the NASA STI program, see the following:

- Access the NASA STI program home page at http://www.sti.nasa.gov

- E-mail your question via the Internet to help@sti.nasa.gov

- Fax your question to the NASA STI Help Desk at 301-621-0134

- Telephone the NASA STI Help Desk at 301-621-0390

- Write to: NASA Center for AeroSpace Information (CASI) 7115 Standard Drive Hanover, MD 21076-1320 
NASA/TM-2007-214704

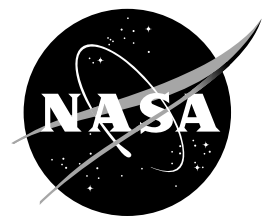

\section{Lunar Simulation in the Lunar Dust Adhesion Bell Jar}

James R. Gaier

Glenn Research Center, Cleveland, Ohio

Edward A. Sechkar

QSS Group, Inc., Cleveland, Ohio

Prepared for the

45th Aerospace Sciences Meeting and Exhibit

sponsored by the American Institute of Aeronautics and Astronautics

Reno, Nevada, January 8-11, 2007

National Aeronautics and

Space Administration

Glenn Research Center

Cleveland, Ohio 44135 


\section{Acknowledgments}

The authors would like to thank B. Banks, P. Greenberg, B. Hillard, D. Jaworske, and A. Wilkinson of the NASA Glenn Research Center, S. Panko of QSS Group, Inc., and F. Lam of Jacobs Sverdrup for their many helpful discussions and suggestions.

Level of Review: This material has been technically reviewed by technical management.

Available from

NASA Center for Aerospace Information 7115 Standard Drive

Hanover, MD 21076-1320
National Technical Information Service 5285 Port Royal Road Springfield, VA 22161

Available electronically at http://gltrs.grc.nasa.gov 


\title{
Lunar Simulation in the Lunar Dust Adhesion Bell Jar
}

\author{
James R. Gaier \\ National Aeronautics and Space Administration \\ Glenn Research Center \\ Cleveland, Ohio 44135 \\ Edward A. Sechkar \\ QSS Group, Inc. \\ Cleveland, Ohio 44135
}

\section{Introduction}

On January 14, 2004, President George W. Bush outlined the Vision for Space Exploration which, among other goals, called for a "human return to the Moon by the year 2020" (ref. 1). This was fleshed out in more detail in the Exploration Systems Architecture Study (ref. 2) which calls for the first lunar landing to be in the year 2018. This is an ambitious schedule given that none of the launch or space vehicles called for by the study presently exist and there are budgetary constraints under which the program must be carried out. If the program is to be successful it must build on the lessons learned during the first human lunar missions, those of the Apollo program.

One of the lessons learned during the Apollo program was that dust on the lunar surface posed a surprisingly broad array of difficulties (ref. 3). There were problems to varying degrees with vision obscuration, equipment clogging, dust coating and abrading, radiator performance degradation, seals failing, and dust inhalation. Apollo 17 astronaut Harrison Schmitt remarked at a lunar simulation workshop in 2005 that, "Dust is the number one environmental problem on the moon" (ref. 4). These effects were a major concern even though the Apollo landers were on the lunar surface for no more than about three days. The early phases of the Exploration program envision missions of seven to fourteen days, with the eventual establishment of a permanent lunar base. Clearly the next human lunar surface missions must be better equipped to deal with the dust.

A specific task has been set up under the Exploration program to develop technologies to mitigate the effects of lunar dust on surface missions. An important aspect of this technology development will be to test possible dust mitigation solutions in a simulated lunar environment on Earth. One of the lessons of Apollo is that these must be high fidelity tests. Dust mitigation technologies that were tested in simulation for Apollo did not always work on the moon. For example, it was thought that using a nylon brush would be an effective way to remove lunar dust from the lunar roving vehicle (LRV) radiator surfaces (ref. 5). However, under lunar conditions the brush did not remove the very fine particles and as a result the thermal performance of the radiator surfaces was degraded significantly in spite of the brushing (refs. 6 to 8$)$.

Three strategies can be employed to mitigate the effects of dust on surface system components. First, components can be designed so that they can better tolerate the effects of dust. An example might be a space suit fabric that has better resistance to abrasion by lunar dust. Second, components can be designed such that less dust attaches to it. For example, a space suit fabric can have a smooth outer layer so that dust cannot so easily work its way between the fibers, so there is less dust on the fabric to abrade it. Third, techniques can be developed to clean dust from surfaces. Perhaps an air shower can be built into the airlock to blow the dust off of the fabric, so it does not abrade the suits. In all likelihood all three strategies will be used in concert. But since the nature of the surfaces of both the dust and spacecraft surfaces are different in the lunar environment that they are in the ambient terrestrial environment, these technologies must be verified in a high fidelity lunar environment simulation chamber.

The lunar dust adhesion bell jar (LDAB) has been built at the NASA Glenn Research Center to provide a high fidelity simulation of the lunar surface environment. Although the principal mission of 


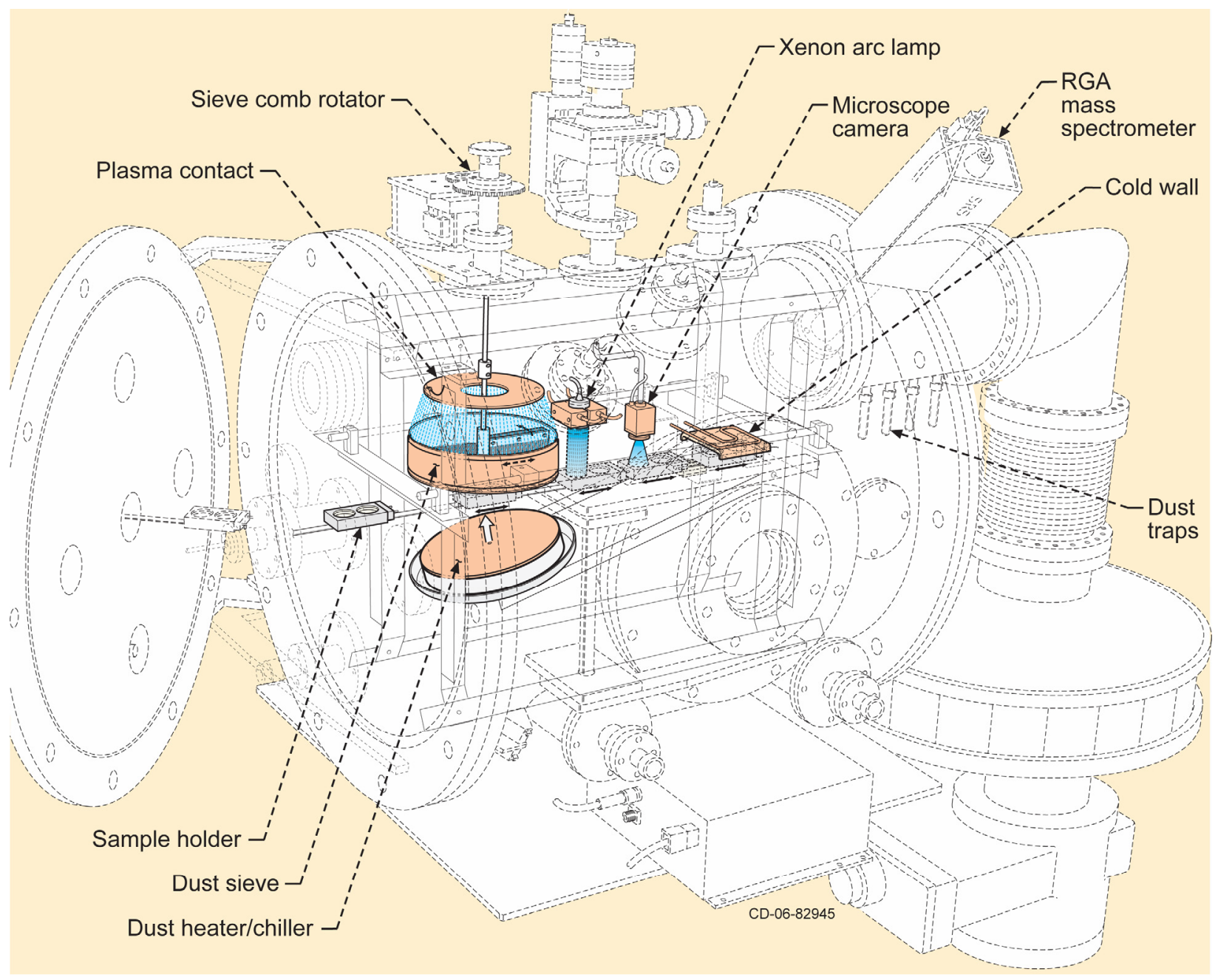

Figure 1.-Cutaway drawing of the lunar dust adhesion bell jar (LDAB) showing the location of the major subsystems.

LDAB is to study the adhesion of lunar dust to spacecraft surfaces, it has been designed with the flexibility to study the effects of lunar dust on the functional properties of candidate materials and surfaces as well. The object of this report is to describe the features required for high fidelity lunar simulation and how these have been incorporated into the facility and operating procedures of the LDAB. A cut-away drawing of the LDAB is illustrated in figure 1, with specific details of the facility described below.

\section{Lunar Simulation}

First, requirements were developed to define what characteristics the lunar simulation environment must have. From the Apollo experience, and aided by an Advanced Integration Matrix study (ref. 9), nine potential dust-caused hazards were identified: vision obscured, equipment clogged, surfaces coated, loss of surface traction, dust inhaled, radiators degraded, instruments fooled, seals failed, and dust abrasion. Two of these, dust inhaled and instruments fooled, were considered to be outside of the scope of this work. But the other seven must have requirements for each environmental factor. Second, requirements might be different for each type of test. In a perfect simulation all constraints would be met in all cases, but each case must be evaluated according to the realities of providing a simulated environment. Five characteristics of the lunar environment were identified as having an important impact on these hazards: the lunar dust, the vacuum environment, the thermal environment, the solar radiation environment, and the reduced gravity environment. 


\section{Lunar Dust Simulant}

The simulation of lunar dust is a complex issue in itself and is the object of intense study. But no matter what material is selected as the lunar simulant, it must be processed in situ to simulate the surface properties it would have on the moon. At the time that the simulant is added to the chamber it will have gases found in the earth's atmosphere adsorbed onto the surface. Most notably, there will be appreciable amounts of water vapor and oxygen. The absence of free oxygen on the lunar surface leads to the fact that transition metals found in the regolith, most notably iron, exist in a reduced state. So at a minimum, post processing must reduce materials to the lunar oxidation state. The continual bombardment of the lunar regolith by high energy radiation will result in many surface atoms being in excited states, which may in turn be important to its cohesive and adhesive properties. So the protocol for post-processing the lunar dust simulant may necessarily be complex. As an example, Olhoeft has used the following sequence (ref. 10):

(1) Perform a controlled pump-down to $10^{-6}$ Torr to prevent dust "explosions" and fluidized bed development

(2) Over-compact and temperature anneal the dust through several cycles of lunar minimum to maximum temperatures during pump-down

(3) During the pump-down and temperature cycling, the solar simulator should cycle on and off as well

(4) Dust must be given sufficient time to thermally equilibrate during temperature cycling

(5) Once pressure is below $10^{-6}$ Torr, create a charged plasma environment

(6) The surfaces of the dust particles need to be radiation damaged into a thin layer of highly reactive, amorphous, glassy material

(7) The earth's magnetic field should be neutralized with external Helmholtz coils

Many of these features have been incorporated into the LDAB design. In order to prevent small dust "explosions" which result from trapped gases, the dust in the LDAB is stirred continuously with a steel comb through all phases of dust processing (fig. 2). First, a vacuum is pulled on the dust in a controlled way to degas loosely-held molecules from the surface of the dust. After a vacuum of $10^{-6}$ Torr is established, the dust is heated with a resistance heater to a temperature of about $200{ }^{\circ} \mathrm{C}$, somewhat above the maximum temperature that dust sees on the moon of about $125^{\circ} \mathrm{C}$, for several hours until the mass

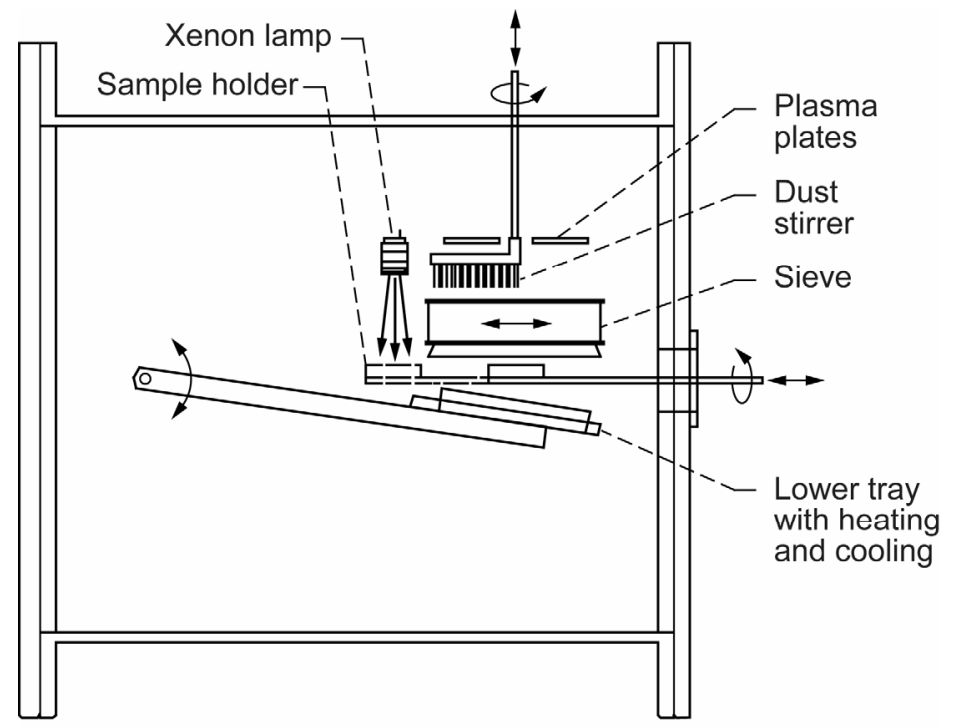

Figure 2.-LDAB dust handling and activation system. 
spectrum of the residual gas remains constant. After this the dust is cooled to about $-150{ }^{\circ} \mathrm{C}$, about the minimum value the dust would see on the moon. The dust is subjected to three thermal cycles, or until there is no change in the mass spectrum of the residual gas.

After the dust has been degassed, the pressure is raised to about $10^{-4}$ Torr and a radio frequency air plasma is generated principally over the dust to clean organic compounds from the surface of the dust particles. This is then replaced by a $\mathrm{H} / \mathrm{He}$ plasma which acts to reduce inorganic surfaces which have been oxidized by the air plasma. It also acts to mimic the solar wind so that if there are adsorbed or implanted species they will be replaced by hydrogen or helium. It is hoped that this combination of plasmas also activates the surface of the dust, creating surface defects and dangling bonds, similar to what is thought to exist on the moon. Once again residual gases are pumped out of the chamber until there are no changes over time.

Dust is next sieved onto the sample. The LDAB is designed to accept standard sieves, so there is control over the particle size that lands on the sample. Also, the sample holder can be rotated so that excess dust can be dumped off of the sample before further testing.

Dust on the sample is next subjected to a solar spectrum of light from a xenon lamp. The dust may suffer additional damage due to the ultraviolet radiation, and with the simultaneous illumination of the sample chemical bonds may be formed between the dust and the sample. This irradiation also heats the sample, which will facilitate bond formation.

What happens next depends on the nature of the sample to be tested. The initial tests will be of radiator materials, so the temperature curves on heating with the xenon lamp and cooling to a $77 \mathrm{~K}$ cold wall will be measured, as well as the steady state temperature when a measured amount of power is applied to them. In other cases the effectiveness of sealing surfaces, or the measurement of adhesion, abrasion, or transmission will be measured.

\section{Vacuum Environment}

For all practical purposes there is no atmospheric pressure on the moon. It is of academic interest whether the pressure is $10^{-10}$ or $10^{-14}$ Torr. There are so few gas phase molecules that on average a surface atom will be impacted by an atmospheric atom about once per day (as opposed to $10^{8}$ collisions per second under earth atmospheric conditions) (ref. 11). In a perfect simulation chamber there would be no pressure. It is worth noting, however, that the local pressure in the immediate vicinity of an EVA suit will not be this low because the suit materials have some gas permeability. It has even been suggested by Landis that human activity could result in an increase in the total lunar atmospheric pressure as high as $10^{-9}$ Torr (ref. 12).

But to achieve even this level of vacuum when the simulation chamber is filled with particulate matter is a challenge. The difficulty is the very large surface area of dust if a significant quantity is to be degassed. There is not a lot of data on chambers that use a significant amount of particulate in vacuo. Apollo Lunar Roving Vehicle (LRV) wheel tests were carried out in a chamber containing about $3000 \mathrm{~kg}$ of particulate, but the pressure was no lower than about 1 Torr (ref. 13). Olhoeft has reported a procedure that has enabled a vacuum as low as $10^{-8}$ Torr with a limited dust sample size (ref. 14). It seems clear that lunar vacuum will not be attainable in a dust-filled vacuum chamber on earth. But what is not as clear is what level of vacuum will be required to mimic the vacuum of the lunar surface. The consequence of having an inadequate vacuum is that gaseous molecules will adhere to surfaces, so that the interaction between the dust particles and the test surface is disrupted. On a molecular level, the question becomes how low a pressure is required for the fractional coverage of adsorbed gases $(\theta)$ to be so low as to not affect the gross surface interactions. There is no universal answer to this question because $\theta$ is a function of the chemical properties of the surface of the dust, the test surface, the nature of the gaseous molecule, and the temperature. Particles which have such low $\theta$ are referred to as "clean bodies", and the behavior differences between clean bodies and bodies acting under atmospheric conditions are referred to as "clean body effects" (ref. 11). 
The basic properties which the quality of the vacuum will affect are the cohesion of the dust, which will dominate loss of surface traction, and adhesion to sensitive surfaces which will dominate vision obscuration, equipment clogging, surfaces coating, radiators degradation, seal failure, and dust abrasion tests.

Insight into the vacuum required to affect the cohesion was found during the LRV wheel tests conducted by Mullis and his team for the Marshall Spaceflight Center in 1971 (ref. 11). It was found during the LRV wheel tests that any time the pressure was less than 5 Torr that the Lunar Soil Simulant 4 (LSS-4, developed by the Army Corps of Engineers) exhibited cohesive clean body effects similar to those reported on the moon. "Clumps of LSS would be thrown up by the wheel and remain as a coherent mass until it struck some solid object, such as the chamber wall. It would then splatter upon impact. A lot of these clumps would stick to the side of the chamber" (ref. 11). Although there were no actual cohesion measurements, this observation tells us that the onset of vacuum cohesion is when the pressure has been reduced to a few Torr. Thus, for properties dominated by cohesion, perhaps the vacuum standard could be set as high as 1 Torr.

Defining the vacuum where adhesive forces are significantly altered is more difficult because of the variation in the chemistry of the various surfaces. There is little doubt that the lower the pressure the more dust-surface combinations will be within the clean body limit. Although a pressure on the order of $10^{-9}$ Torr (the upper limit of estimated lunar pressure) would be desired, perhaps a pressure in the $10^{-7}$ Torr range is all that can reasonably be achieved when large quantities of granular particles are used. In designing the LDAB it was decided that this level of vacuum could be provided by an oil diffusion pump with a liquid nitrogen cold cap. The oil diffusion pump has the additional advantage of being robust to any dust that would find its way into it.

Indeed, one of the innovative design features of LDAB is its system of baffles and offsets which limit the transport of dust into the pump. Figure 3 illustrates the basic features. First note that the chamber is

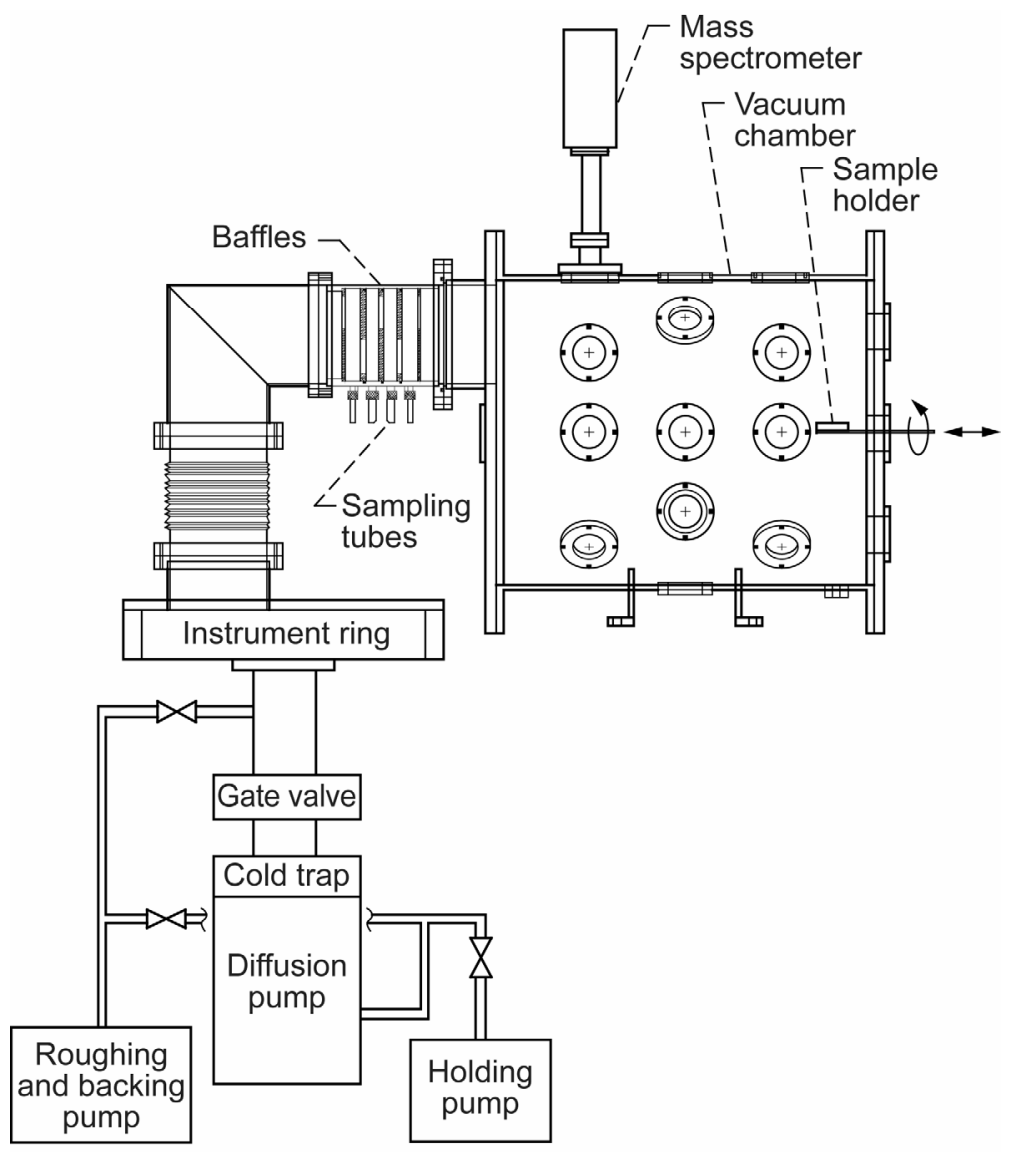

Figure 3.-LDAB vacuum pumping and monitoring system. 
pumped from near the top. Under vacuum, dust will fall ballistically, and since the bottom of the vacuum vent opening is above the dust reservoir, no dust should be able to flow to the pump. However, when vacuum is being first established, the dynamic pressure of the retreating air could conceivably carry some dust to the vent. As can be seen in figure 2, the first part of that vent is horizontal, and within it are five baffles with alternating windows at the top-bottom-top-bottom-top. Between the baffles are glass sampling tubes used to monitor the amount of dust being transferred through the baffle system. Finally, the vent bends downward and empties into an instrument ring antechamber. This is directly pumped by the diffusion pump, but the vent to the pump is offset from that entering the antechamber. The cold cap on the diffusion pump, in conjunction with the baffle system just described limits the amount of backstreaming of pump oil back into the chamber. A quadrupole mass spectrometer residual gas analyzer located in the chamber is able to detect pump oil at a partial pressure of about $10^{-11}$ Torr.

\section{Temperature Environment}

According to the Lunar Sourcebook (ref. 15) the average temperature of the regolith at the equator of the moon is $253 \mathrm{~K}$, and ranges from $93 \mathrm{~K}$ on the night side to $396 \mathrm{~K}$ in the unshaded day. Near the poles the average temperature is $218 \mathrm{~K}$ and ranges from $53 \mathrm{~K}$ at night to $213 \mathrm{~K}$ during the day. The bottoms of permanently shadowed craters near the poles have a temperature of about $43 \mathrm{~K}$. Thus, the temperature range required for the simulation depends strongly on the geography of the mission being simulated. But to be able to test for all environments, a range of 40 to $400 \mathrm{~K}$ is required.

It is important to note that the temperatures noted above are regolith temperatures. The equilibrium temperature of equipment, such as space suits, will depend largely on the optical properties of its surface. The bulk of solar radiation is in the visible region (400 to $700 \mathrm{~nm})$ and so this region will dominate absorption $(\alpha)$. The suit will also emit radiation whose wavelength will depend on its surface temperature. This temperature depends both on the radiative heat load from the absorption and on the internal heat generated by the astronaut or equipment. Tolerable temperatures for both humans and most equipment dictate that the emission $(\varepsilon)$ will be dominated by infrared radiation $(2$ to $5 \mu \mathrm{m})$. So the temperature of equipment will be determined by the radiative heat load, the internal heat load and by the value of $\alpha / \varepsilon$ of their surfaces.

The efficiency of emission also depends on the temperature being emitted to. Because of the lack of atmosphere, the radiative temperature of the sky (except for the direct view of the sun) will be that of space, or about $4 \mathrm{~K}$. The radiative temperature of the surface is as discussed above. So a good thermal simulation would require a sky view near $4 \mathrm{~K}$ and a ground view in the range of 40 to $400 \mathrm{~K}$, depending on the region being simulated and the elevation of the sun. By application of the Stefan-Boltzmann law, the equilibrium temperature at $1 \mathrm{AU}$ from the sun is about $270 \mathrm{~K}$, so perhaps this value would be representative of the average temperature.

Another feature of the daytime lunar environment is that of temperature extremes between the lit and shadowed areas during the day which may vary by as much as $200 \mathrm{~K}$ (from 155 to $355 \mathrm{~K}$ ) over a distance of a few $\mathrm{cm}$. This will be important for large structures that may be partially shadowed during parts of the lunar day.

The temperature range will have effects on many properties. Materials will have to be able to endure the thermal cycling that will occur as equipment moves between light and shadow. The cohesive and adhesive forces of the dust may well be temperature dependent. The efficiency of radiators and other thermal control surfaces will vary over a wide range depending on whether they are radiating to free space or if their view is dominated by sunlit regolith. Realistic thermal simulation will be important to predict the performance of equipment.

For the most part, equipment will not be expected to reach temperatures lower than the regolith. So the temperature range over which surface traction, vision obscuration, equipment clogging, surfaces coating, seal failure, and dust abrasion tests should be carried out is over the range of regolith temperatures, 40 to $400 \mathrm{~K}$. As a practical matter, most tests could probably be carried out at temperatures 


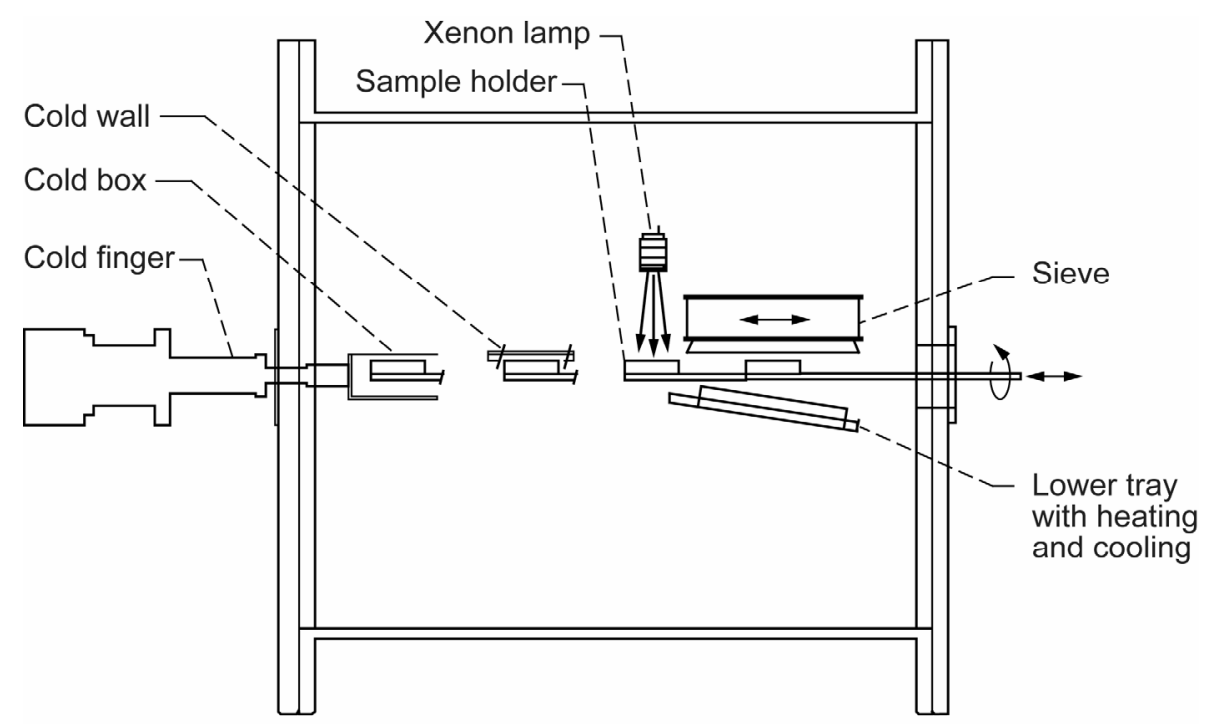

Figure 4.-LDAB thermal monitoring and control system.

no lower than liquid nitrogen $(77 \mathrm{~K})$ and this would cover the most likely scenarios that materials would likely encounter.

The configuration of the LDAB is such that there is only a few $\mathrm{cm}$ distance between the region lit and heated by the xenon lamp and the liquid nitrogen cooled cold wall (see fig. 4). Plans are underway to install a cryobox that will be able to be chilled to $40 \mathrm{~K}$ to enable the simulation of temperatures in permanently shadowed polar craters. Thus, the requirement to have such high and low temperatures in close proximity will be met.

\section{Solar Radiation Environment}

Nearly all external energy deposited on the equipment on the lunar surface will come from solar radiation. The low energy end of the electromagnetic spectrum, up through visible light, is not expected to affect materials except through thermal effects, which have already been discussed. Higher energy light, especially in the ultraviolet range (100 to $400 \mathrm{~nm}$ ) has the potential to cause chemical reactions because their energies are resonant with chemical bond energies. The work function of lunar simulants, which have a very similar chemistry to lunar regolith, has been measured to be in the range of $5.8 \mathrm{eV}$, which corresponds to an excitation radiation of about $214 \mathrm{~nm}$ (ref. 16). Most materials are relatively opaque in the ultraviolet and so the energy is deposited near the surface. Thus, with the exception of transparent materials, ultraviolet degradation is mostly a surface phenomenon. As light energy increases into the $\mathrm{x}$-ray and gamma ray region it is less likely to interact with the molecules and so can penetrate further into the material before being absorbed by inner shell electrons. Very high energy electromagnetic radiation may pass through materials and equipment with no interaction.

Since the solar electromagnetic radiation does have the potential to change materials and surfaces, it is recommended that a solar simulator be a part of the lunar simulation environment. A xenon arc lamp will simulate not only the ultraviolet constituent (at least for wavelengths above $200 \mathrm{~nm}$ ), but also the visible and infra-red, and so simulate how components will be radiatively heated by the sun on the lunar surface. Additional heating to represent the internal heat load may be required as well to simulate realistic operating temperatures.

In addition to electromagnetic radiation the sun also emits a spectrum of high energy particles, including electrons and positively charged ions, mostly hydrogen with some helium, but also small amounts of other heavy nuclei (particularly in the lowest energy part of the spectrum) (ref. 17). This flux 
of ions is referred to as the solar wind, and on the lunar surface is about $3 \times 10^{8}$ ions $/ \mathrm{cm}^{2}$-sec (ref. 18). In addition, there are other very high energy ions which do not come from the sun, but in fact seem to come from all directions, referred to as galactic cosmic rays. Like the high energy electromagnetic radiation, cosmic rays are so energetic that most will pass through spacecraft without interacting. These are more worrisome from a medical viewpoint, because of the ability to cause mutations in DNA, than they are from an equipment standpoint (ref. 19).

The sun is not a static entity, and so its output is also not static. Although there is little variation in the electromagnetic radiation (except in the x-ray region) solar storms can increase the particle flux dramatically. The solar magnetic field above sun spots can become unstable and lead to an explosion or "solar flare". This results in a coronal mass ejection of gas, mostly hydrogen, which then streams out from the sun which in turn causes a shock wave in the solar wind which, when it passes an object is known as a solar particle event (SPE). SPEs cause dramatic increases in the radiation dose over quiescent solar conditions, and are dangerous radiation sources for a short-term mission (ref. 20).

The solar illumination environment will be supplied by a xenon lamp which provides a near-solar spectrum from the ultraviolet $(200 \mathrm{~nm})$ into the infrared $(1200 \mathrm{~nm})$. Due to the difficulty of producing energetic electromagnetic radiation (x-rays and $\gamma$-rays) and particles (electrons and hydrogen and helium nuclei) in as compact a facility as LDAB, that aspect of the lunar environment will not be well simulated in LDAB. Some of the effects of the radiation, however, such as chemically active surfaces and gases implanted in the dust will be generated by the radio frequency plasmas described above. In some circumstances, specific radiation tests may be carried out at high energy physics facilities such as the synchrotrons and particle accelerators.

\section{Reduced Gravity Environment}

Because of its smaller mass, the acceleration due to gravity on the moon is only 0.165 that of earth, or about one-sixth. This, coupled with the lack of an atmosphere, means that the transport of dust on the moon is considerably different from that of dust on the earth. The material properties of the dust, however, are probably not affected by the reduced gravity.

It is an open question to what extent the reduced gravity affects dust adhesion to surfaces. There is no reason to believe that gravitational forces affect adhesion, but one of the central dust removal mechanisms is dust being pulled off surfaces by gravity. Thus, any surface to which dust sticks in a 1-g environment, it will also stick to in a 1/6-g environment. However, mitigation strategies could be developed that shed dust well in 1-g, which would be ineffective in 1/6-g.

Testing in reduced g-loads is difficult and expensive. Although the LDAB could be flown in an aircraft on the parabolic flight profile (ref. 21) this would require considerable expense to outfit the aircraft with full utilities including liquid nitrogen. At this time it does not seem to be a prudent use of resources.

\section{Conclusions}

The Lunar Dust Adhesion Bell Jar has been assembled at the NASA Glenn Research Center to provide a high fidelity lunar simulation facility to test the interactions of lunar dust and lunar dust simulant with candidate aerospace materials and coatings. It has a sophisticated design which enables it to treat dust in a way that will remove adsorbed gases and create a chemically reactive surface. It can simulate the vacuum, thermal, and radiation environments of the moon, including proximate areas of illuminated heat and extremely cold shadow. It is expected to be a valuable tool in the development of dust repellant and cleaning technologies for lunar surface systems. 


\section{References}

1. G.W. Bush, A Renewed Spirit of Discovery: The President's Vision for U.S. Space Exploration (2004).

2. NASA's Exploration Systems Architecture study, NASA/TM-2005-214062.

3. J.R. Gaier, The Effects of Lunar Dust on EVA Systems During the Apollo Missions, NASA/TM2005-213610.

4. H. Schmitt, The Apollo Experience/Problems Encountered with Lunar Dust, Biological Effects of Lunar Dust Workshop, Sunnyvale, CA (2005).

5. Jacobs, S., Durkee, R.E., and Harris, R.S., "Lunar Dust Deposition Effects on the Solar Absorptance of Thermal Control Materials," AIAA Paper 71-479 presented at the AIAA 6th Thermophysics Conference, Tullahoma, TN, April 1971.

6. McKay, G.H., Chairman, "Saturn V Launch Vehicle Flight Evaluation Report-AS-510, Apollo 15 Mission," Saturn V Flight Evaluation Working Group, 1971.

7. McKay, G.H., Chairman, "Saturn V Launch Vehicle Flight Evaluation Report-AS-511, Apollo 16 Mission," Saturn V Flight Evaluation Working Group, 1972.

8. McKay, G.H., Chairman, "Saturn V Launch Vehicle Flight Evaluation Report-AS-512, Apollo 17 Mission," Saturn V Flight Evaluation Working Group, 1973.

9. S. Wagner, et al., An Assessment of Dust Effects on Planetary Surface Systems to Support Exploration Requirement, CTSD-AIM-0029, NASA Johnson Space Center (2004).

10. G. Olhoeft, Colorado School of Mines, Golden, CO, personal communication (2005).

11. Calculated using kinetic molecular theory see, for example, P.W. Atkins, Physical Chemistry, 6th Ed (1998) pp. 851-852.

12. G.A. Landis, Degradation of the Lunar Vacuum by a Moon Base, Act Astronautica 21(3) (1990) pp. $183-187$.

13. C.H. Mullis, Final Report on Contract NAS8-26175, "A Study and Analysis of the MSFC Lunar Roving Vehicle Dust Profile Test Program” (1971).

14. G. Olhoeft et al., "Effects of Water on the Electrical Properties of Lunar Fines," Proc. Lunar Sci. Conf. 6th, (1975) p. 3333.

15. W.D. Carrier, III et al., The Lunar Sourcebook (Cambridge University Press, 1991).

16. Z. Sternovsky, S. Robertson, A. Sickafoose, J. Colwell, and M. Horányi, Contact Charging of Lunar and Martian Dust Simulants, J. Geophys Res. 107(E11) (2002), pp. 15-1 to 15-8.

17. Apollo Program Summary Report, NASA TM-X-68725 (1975) pp. 3-62.

18. R.J. Williams and J.J. Jadwick, "Handbook of Lunar Materials," NASA Reference Pub 1057 (1980) p. 93.

19. J. Wilson et al., NASA Ref Pub 1257, Transport Methods and Interactions for Space Radiations (1991).

20. F.A. Cucinotta, M-H.Y. Kim, and L. Ren, NASA/TP—2005-213164, Managing Lunar and Mars Mission Radiation Risks Part I: Cancer Risks, Uncertainties, and Shielding Effectiveness (2005).

21. http://exploration.grc.nasa.gov/ground/flight_aircraft.html (accessed Aug 2005). 


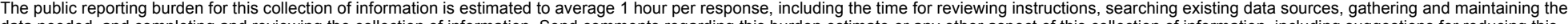

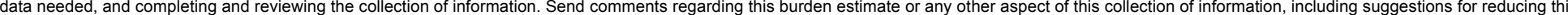

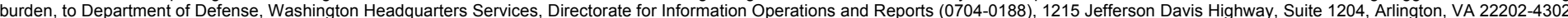

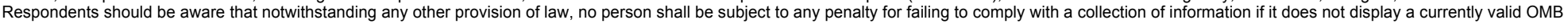
control number.

PLEASE DO NOT RETURN YOUR FORM TO THE ABOVE ADDRESS
1. REPORT DATE (DD-MM-YYYY)
2. REPORT TYPE
3. DATES COVERED (From - To)

14-06-2007

\section{TITLE AND SUBTITLE}

Lunar Simulation in the Lunar Dust Adhesion Bell Jar

5b. GRANT NUMBER

5c. PROGRAM ELEMENT NUMBER

6. AUTHOR(S)

Gaier, James, R.; Sechkar, Edward, A.

\section{5d. PROJECT NUMBER}

5e. TASK NUMBER

5f. WORK UNIT NUMBER

WBS 083229.02.99.05

\section{PERFORMING ORGANIZATION REPORT NUMBER}

E-15929

National Aeronautics and Space Administration

John H. Glenn Research Center at Lewis Field

Cleveland, Ohio 44135-3191

\section{SPONSORING/MONITORING AGENCY NAME(S) AND ADDRESS(ES)}

National Aeronautics and Space Administration

Washington, DC 20546-0001

\section{TPONSORING/MONITORS ACRONYM(S) \\ NASA}

\section{SPONSORING/MONITORING} REPORT NUMBER

NASA/TM-2007-214704; AIAA-20070963

\section{DISTRIBUTION/AVAILABILITY STATEMENT}

Unclassified-Unlimited

Subject Category: 14

Available electronically at http://gltrs.grc.nasa.gov

This publication is available from the NASA Center for AeroSpace Information, 301-621-0390

\section{SUPPLEMENTARY NOTES}

\section{ABSTRACT}

The Lunar Dust Adhesion Bell Jar has been assembled at the NASA Glenn Research Center to provide a high fidelity lunar simulation facility to test the interactions of lunar dust and lunar dust simulant with candidate aerospace materials and coatings. It has a sophisticated design which enables it to treat dust in a way that will remove adsorbed gases and create a chemically reactive surface. It can simulate the vacuum, thermal, and radiation environments of the Moon, including proximate areas of illuminated heat and extremely cold shadow. It is expected to be a valuable tool in the development of dust repellant and cleaning technologies for lunar surface systems.

\section{SUBJECT TERMS}

Lunar environment; Lunar dust

\section{SECURITY CLASSIFICATION OF:}

\section{a. REPORT}

$\mathrm{U}$

\section{b. ABSTRACT} U
17. LIMITATION OF ABSTRACT

18. NUMBER
OF
PAGES
15

19a. NAME OF RESPONSIBLE PERSON

James R. Gaier

19b. TELEPHONE NUMBER (include area code) $216-433-6686$ 

